\title{
Felipe Melanchton e a Experiência da Reforma Protestante: Caminhos e Descaminhos
}

\author{
Paulo Samuel Albrecht
}

\section{Resumo}

Uma das grandes figuras da Reforma do século XVI foi Felipe Melanchton. Ele era um humanista que veio a se tornar teólogo e deu importantes contribuições à reforma religiosa na Alemanha e em outras partes, com seus muitos contatos em muitos países e com suas obras teológicas, como o Loci Communes e a Confissão de Augsburgo e sua Apologia. Suas contribuições freqüentemente são obscurecidas pela grande figura de Martinho Lutero, mas nós podemos perceber que ele também teve sua influência na Reforma como um todo e mesmo sobre o próprio Lutero, contribuindo com o seu impressionante domínio de Grego, Latim e Retórica, e também com seus insights teológicos.

Melanchton foi o sistemático do movimento luterano, moldando o pensar teológico por décadas, ao menos até o fim do século XVI. Sofreu, ainda, grandes dissabores quando foi acusado de trair a fé luterana em dois momentos: ao editar uma versão alterada da Confissão de Augsburgo, em 1540 (Variata) e com o Ínterim de Leipzig, de 1548. Contudo, em todo o seu proceder, vemos um homem de grande conhecimento que tinha um grande amor pela Palavra de Deus e pela Igreja, sempre disposto ao diálogo e entendimento através de sua moderatio. 
Palavras-chave: Reforma, Melanchton, Experiência Religiosa, Conflito.

\begin{abstract}
One of the greatest figures in the XVI Century Reformation was Philip Melanchthon, a humanist who later became a theologian and gave important contributions to Reformation in Germany and beyond, with his many contacts in many countries and his theological works, such as Loci Communes and the Confession of Augsburg and its Apology. His contributions are often shadowed by the towering figure of Martin Luther, but by taking a closer look we can see he had a great influence on the Reformation as a whole and even on Luther himself, through his outstanding mastery of Greek, Latin and Rhetoric and his theological insights.

He was the systematician of the Lutheran movement and molded the way of theological thinking for decades, at least until the end of the XVI century. He also underwent a lot of distress as he was accused of betraying the Lutheran faith at two points: in his altered version of the Augsburg Confession of 1540 (Variata) and with the Leipzig Ínterim of 1548. However, in all his dealings, we see a man of great learning who had a great love for the Word of God and for the Church, always willing to reach out in moderatio.
\end{abstract}

Keywords: Reformation, Melanchton, Religious Experience, Conflict.

Não há como falar da Reforma Protestante na Alemanha sem falar de Felipe Melanchton (1497-1560). Muitas vezes incompreendido, julgado abruptamente tanto por luteranos quanto por católicos, Melanchton na verdade foi uma figura soberba do século XVI que trouxe grande contribuição para o cenário religioso da Europa Ocidental. Enquanto muitos humanistas que viam abusos e incongruências na Igreja Cristã não assumiam abertamente seu descontentamento, esposando apenas uma reforma pessoal e não da igreja como um todo ${ }^{1}$, ele tomou partido ao lado da reforma luterana na Alemanha e assumiu as suas consequências. Mesmo assim, isso não o impediu de sempre buscar a concórdia e o diálogo, considerando-se um fiel filho da Igreja Católica (Universal).

\footnotetext{
${ }^{1}$ Cf. OLIN, J. C., The Catholic Reformation: Savonarola to Ignatius Loyola. New York, Fordham University Press, 1992, p. XVI-XVII.
} 
Antes de mais nada, Melanchton era um humanista. Adorava os clássicos gregos e latinos. Recebeu seu grau de bacharel aos 14 anos pela universidade de Heidelberg e aos 17 anos o de mestre, pela universidade de Tübingen. Permaneceu na faculdade de Tübingen por 4 anos até aceitar, em 1518, a posição de professor na Universidade de Wittenberg, a qual havia sido fundada pelo eleitor da Saxônia em 1502. Tomava parte do movimento humanista que varria a Europa e que encontrava em Erasmo o seu maior expoente ${ }^{2}$. Estudava Cícero e Aristóteles e editou diversas obras deles. Tinha interesse em preparar uma edição das obras completas de Aristóteles, mas acabou dissuadido por Lutero $^{3}$. Lecionou um amplo espectro de disciplinas, o que evidenciava seu grande e variado interesse. Seu sobrenome evidencia o seu humanismo e gosto pelas línguas clássicas, uma vez que Melanchton é a tradução grega de seu nome alemão, Schwarzerd.

Dizer que Melanchton só assumiu ideias reformatórias após chegar a Wittenberg seria impreciso. Logo em sua chegada na universidade de Wittenberg, proferiu um discurso no qual defendia a correção da educação da juventude ${ }^{4}$. Em Wittenberg foi ganho para a causa da reforma eclesiástica, claramente sob a influência de Lutero. Porém, não podemos menosprezar a influência mútua entre ambos. Os conhecimentos de grego, latim, dos pais eclesiásticos e de retórica de Melanchton são inestimáveis contribuições para o movimento reformatório e para Lutero. Como Kolb coloca:

When Melanchthon came to Wittenberg in 1518, his learning and his wisdom won Luther's admiration almost immediately. Through Melanchthon's erudition in the Biblical languages, Luther grew in his own understanding of biblical vocabulary, including concepts like "justification" and "faith". Melanchthon, on the other hand, gained new insights into the Gospel through his conversations with Luther and incorporated them into his own way of thinking. Luther brought techniques of medieval scholasticism to the study of Scripture and the Christian tradition, and Melanchthon enriched their common enterprise

\footnotetext{
${ }^{2}$ Segundo o hebraísta Reuchlin, não havia ninguém na Alemanha que superasse Melanchton em grego e também em latim. Considerava até que ele havia superado Erasmo. Cf. WRIEDT, M. Between Angst and Confidence: Melanchton as a Man of the Sixteenth Century, Concordia Journal 23 (1997), p. 281.

${ }^{3}$ MELANCHTON, F., Loci Communes. Saint Louis, Concordia Publishing House, 1992, Traduzido por J. Preuss. Prefácio do tradutor, p.8.

${ }^{4}$ Ibidem, p. 8.
} 
of interpreting the Biblical message and the catholic faith in their situation with the insights and the movement we call Biblical Humanism"5

Em Wittenberg, Melanchton estuda teologia e adquire o seu bacharelado, sob forte influência e estímulo de Lutero. Este insiste para que Melanchton também tome sob sua responsabilidade a docência na área da teologia. Torna-se também teólogo, embora nunca venha a ser ordenado sacerdote. Embora sempre considerado sombra de Martinho Lutero, encontra-se nele primeiramente a ênfase forense da justificação pela fé, em suas teses para conseguir o título de bacharel em teologia, em $1519^{6}$. Alguns até afirmam que ele precedeu Lutero no desenvolvimento do famoso Sola Scriptura ${ }^{7}$. Acrescente-se a isso o fato de nunca ter sido ordenado sacerdote, ou seja, compartilhava daquilo que Lutero propunha como o sacerdócio universal de todos os crentes, e se tem aí em uma só pessoa as 3 grandes forças que alavancaram a Reforma na Alemanha e também na Europa, de acordo com Delumeau 8 .

Sua maior contribuição teológica para a Reforma, indubitavelmente, torna-se seu Loci Communes, ou os Lugares Comuns da teologia, uma exposição ordenada e pormenorizada dos principais pontos da teologia. Este livro apareceu em 1521 e logo se tornou o livro-texto de todas as universidades teológicas do movimento protestante. Ele foi depois revisado e teve novas edições, em 1535 e depois em 1543, demonstrando que Melanchton era um teólogo insatisfeito, sempre buscando polir e melhorar suas obras. Esta obra, bem como depois a Confissão de Augsburgo e a Apologia da Confissão, mostram a paixão e zelo que Melanchton tinha pela ordem e organização. Tanto aquela obra, como estas duas, são organizadas de formas tópicas e com uma lógica e encadeamento próprio. Elas revelam a preocupação do "professor" Melanchton: "But Melanchton organized material for better learning, for improved preaching and teaching by his students when they became pastors".?

Esta paixão de Melanchton pela ordem e método, a sua preocupação pedagógica para com seus alunos, fez com que ele fosse cognominado, ainda

\footnotetext{
${ }^{5}$ KOLB, R., Philipp Melanchthon: Reformer and Theologian, Concordia Journal 23 (1997), p. 310.

6 "Thesis 10: All our righteousness is a gracious imputation of God". MELANCHTON, p. 10.

7 "Theses 16 and 17, "It is not necessary for a Catholic to believe in any other articles of faith than those to which Scripture is a witness," and "The authority of councils is below the authority of Scripture." MELANCHTON, Loci Communes. Prefácio do tradutor, p. 10.

${ }^{8}$ DELUMEAU, J., Nascimento e Afirmação da Reforma. São Paulo, Pioneira, 1989, Traduzido por João Mendes Campos, p. 60-83.

${ }^{9}$ KOLB, R., Philip Melanchton, p. 311
} 
no século XVI, de Praeceptor Germaniae. Ele foi professor em Wittenberg de 1518 a 1560. Por ele passaram as grandes mentes e os líderes do movimento luterano. Com a morte de Lutero, em 1546, ele naturalmente assumiu a liderança teológica do movimento luterano. Embora muitos pontos de sua teologia sejam contestados, especialmente dentro de círculos luteranos, os principais teólogos luteranos foram formados por Melanchton e aprenderam a fazer teologia com ele. Mesmo que discordassem do Praeceptor, teriam que fazê-lo de acordo com a cartilha dele! Isto é visto de forma muito clara na Fórmula de Concórdia, do final do século XVI, que resolveu diversos conflitos intra-luteranos, vários deles causados pela teologia de Melanchton no que tange o livre-arbítrio, as boas obras e a doutrina da Ceia e a Cristologia ${ }^{10}$. Para entendermos, sigamos a explicação de Wengert:

From the 1520s, nearly every Latin school in Evangelical territories (and many outside them) used his primers on grammar, rhetoric and logic. Using Melanchthon's method became as obvious as speaking or writing in German or Latin. In the Formula [of Concord], the authors divided the issues according to - using Melanchthon's own term - loci communes, commonplaces or major topics and general themes of theology: original sin, free will, justification, good works, law and gospel, third use of the law, the Lord's Supper, and Christology. Moreover, with the possible exception of articles eleven and twelve, they organized the topics basically according to Melanchthon's own order, employed in his Loci Communes theologici itself. More than that, they constructed individual loci and their arguments using Scripture, the Church Fathers, and experience as Melanchthon had taught, especially in the Loci communes. Finally, they also prosecuted their arguments using the very logical syllogism in which Melanchthon himself had trained them. ${ }^{11}$

\footnotetext{
${ }^{10}$ Com a Fórmula de Concórdia, luteranos tentaram resolver as discordâncias que surgiram em seus territórios entre 1540 e 1577 . Após o surgimento da Fórmula, os luteranos reuniram seus principais documentos no Livro de Concórdia, de 1580. Este constituía o "Corpus Doctrinae" luterano. Segundo Dingel, esta própria busca por tal corpo de doutrina reflete a influência e importância de Melanchton, pois seus seguidores foram os primeiros a coletar um "Corpus Doctrinae" com as obras de Melanchton, o "Corpus doctrinae Phillipicum". Cf. DINGEL, I., The Preface of the Book of Concord as a Reflection of Sixteenth-Century Confessional Development, Lutheran Quarterly XV (2001) p.378-9.

11 WENGERT, T., Bearing Christ as Melanchton's Contribution to the Book of Concord, Lutheran Quarterly XV (2001), n.4 (Winter 2001), p. 400.
} 
Com a excomunhão em 1521 e sua proscrição do império após a Dieta de Worms, Lutero não pôde participar da Dieta de Augsburgo, em 1530, pela qual Carlos V queria solucionar o cisma luterano. Melanchton, então, aparece como a principal figura teológica em Augsburgo, onde os príncipes luteranos são intimados a retornarem à Igreja Católica Romana. Foi ele quem redigiu a confissão de fé apresentada diante do imperador Carlos V e quem depois escreveu a defesa da confissão, chamada de Apologia, como resposta à confutação que a parte católica apresentou à confissão luterana. Esta apologia só veio a ser publicada em 1531, após esmerado trabalho de Melanchton ${ }^{12}$. $\mathrm{Na}$ formulação da confissão evidencia-se o tom irênico e conciliador de Melanchton, inclusive na disposição que ele faz dos temas, trazendo nos 21 primeiros artigos pontos em que acreditava haver consenso com a igreja universal, deixando os últimos 7 artigos para tratar dos temas polêmicos, que diziam mais respeito a abusos e práticas que eram consideradas inapropriadas à Igreja. Melanchton apresenta assim a sua confissão, que não é só sua, mas do movimento luterano, num sincero desejo de expressar a catolicidade do mesmo dentro da Igreja. Não há nem como imaginar qual seriam as consequências se fosse Lutero a redigir a confissão!

O tom irênico e diplomático do reformador e também humanista alemão podem ser vistos especialmente nos seus muitos contatos dentro e fora da Alemanha. A busca pela unidade exterior da Igreja Cristã era sempre uma preocupação sua, embora tenha sido severamente criticado por parecer demonstrar inconstância com esta sua atitude:

In inter-church relations Melanchthon looked in all directions. He carried on extensive negotiations with the Romanists and with the Reformed, both Zwinglians and Calvinists. He corresponded with the patriarch of Constantinople. He dedicated one of his revisions of the Loci Communes to Henry VIII of England. He was on very good terms with Calvin and many Crypto-Calvinists. He drew the line only at the Anabaptists, the Unitarians, and the Lutherans with whom he disagreed. ${ }^{13}$

\footnotetext{
${ }^{12}$ Não foi permitido aos príncipes luteranos apresentarem uma resposta à confutação na dieta. Cf. Ibidem, p. 409-10.

${ }^{13}$ PREUS, J. The Second Martin: The Life and Theology of Martin Chemnitz. Saint Louis, Concordia Publishing House, 1994, p. 48. Preus dá destaque para os encontros que Melanchton teve com católicos romanos, especialmente em 1541,em Regensburg; em 1557 em Worms, além da dieta em Augsburgo, em 1530, por ocasião do Ínterim de Leipzig, em1548 e de seu comparecimento ao Concílio de Trento, como mencionado ao longo do trabalho. A edição do Loci Communes
} 


\section{Descaminhos}

Anos depois, a Confissão de Augsburgo seria objeto de polêmica. Melanchton continuou a melhorar o seu trabalho, o que não era visto com estranheza pelos seus colegas, nem por Lutero, mas que foi motivo de celeuma após a sua morte, em 1560, por razões políticas. Dos melhoramentos que promoveu na Confissão de Augsburgo, surgiu uma nova edição, a de 1540, também chanada de Variata. Nela Melanchton teria alterado o teor da confissão, especialmente no artigo $\mathrm{X}$, que trata da Ceia, possibilitando uma interpretação reformada da mesma. Este foi um assunto candente especialmente após 1555, quando foi assinada a Paz de Augsburgo, que reconhecia legalmente apenas a Igreja Católica e a Igreja da Confissão de Augsburgo. Diversos ramos reformados procuraram encontrar amparo, então, na Confissão de Augsburgo e conseguiram fazê-lo através da edição Variata, especialmente o príncipe eleitor Frederico III do Palatinado, que havia se tornado calvinista e tentou usar a Variata para ganhar reconhecimento político na década de 1560 . Devido a questões políticas, de calvinistas buscando amparo neste texto de Melanchton, a Variata foi rejeitada em campos luteranos, e aderiu-se ao texto de 1530, trazendo grande descrédito para Melanchton e contribuindo para alguns vê-lo como traidor. Porém, vale ressaltar que antes da questão política entrar em cena, não houve dissenso sobre a Variata na Alemanha, pelo contrário, valorizava-se os esforços de Melanchton de manter a confissão do movimento evangélico (luterano) sempre atualizada ${ }^{14}$.

Contudo, o aspecto mais controverso da carreira de Melanchton aconteceu depois que assumiu a liderança do movimento luterano, após o falecimento de Martinho Lutero, em 1546. O imperador Carlos V estava, finalmente, desembaraçado de seus adversários e podia agir contra os luteranos. Juntou o seu exército e com a ajuda do Duque Moritz da Saxônia, ao qual foi prometido o governo da Saxônia Eleitoral para que se juntasse às forças do imperador, derrotou as forças luteranas do eleitor da Saxônia e de Felipe de Hesse. Após sua vitória, Carlos V impôs em terras luteranas o Ínterim de Augsburgo, em 1547, documento que deveria valer no ínterim entre a sua promulgação e a decisão oficial do Concílio de Trento que havia sido conclamado. Este Ínterim ordenava o retorno imediato dos luteranos para a Igreja Católica Romana,

dedicada a Henrique VIII foi a de 1535. Para mais informações sobre as inclinações ecumênicas de Melanchton, ver PREUS, op. cit., pp. 48-56.

${ }^{14}$ Cf. KOLB. Philip Melanchton, p. 313-14. 
retomando novamente as práticas e costumes que haviam sido abandonados.

Houve dificuldades, pois Moritz, agora eleitor da Saxônia, havia sido assegurado de que poderia professar sua fé luterana após a vitória, porém tal promessa fora revogada e foi-lhe ordenado obedecer ao Ínterim de Augsburgo. Ele, então, pediu a Melanchton e outros teólogos e conselheiros para formularem uma alternativa ao Ínterim, que atendesse à ordem do imperador e também à profissão de fé evangélica na Saxônia. Esta foi terminada em 1548 e ficou conhecida como o "Ínterim de Leipzig". Este foi implantado parcialmente nas terras de Moritz. Utilizando o conceito de "adiaphora", isto é, coisas indiferentes, ele tentou atender ao Ínterim de Augsburgo, ao mesmo tempo em que procurava preservar a doutrina da justificação. Para isso, bastava que os "adiaphora" fossem aceitos, isto é, práticas e cerimônias exteriores. O propósito último de Melanchton na formulação do Ínterim de Leipzig era tentar evitar a ocupação das terras alemãs pelos soldados imperiais e a consequente eliminação do luteranismo, ao dar uma aparência católica romana às igrejas saxãs em suas práticas e cerimônias eclesiásticas.

Muitos se sentiram traídos pela atitude de Melanchton, pois rejeitavam o conceito de adiáforo, dizendo que em época de perseguição religiosa nenhuma doutrina ou prática eclesiástica se tornava indiferente. Conceder num só ponto seria negar a fé. As controvérsias dentro dos próprios campos luteranos aumentaram e muitos discípulos de Melanchton o consideraram um traidor. Dois grandes "partidos" emergiram, os gnésio-luteranos, ou verdadeiros luteranos, contrários à suposta traição do luteranismo por Melanchton, e a dos filipistas, defensores da teologia e da pessoa de seu mestre. Também é interessante notar que, neste mesmo período, Melanchton compareceu diante do concílio de Trento, em 1551, mas sem grande repercussão. Neste encontro entregou a confissão feita por ele e seus colegas intitulada "Uma Repetição da Confissão de Augsburgo"15.

\section{A Experiência e o Aprendizado}

O que podemos aprender de Melanchton, à medida que acessamos a sua contribuição para a experiência religiosa num contexto de pluralismo religioso e diálogo ecumênico? A primeira coisa que podemos ressaltar é a sua coragem para reconhecer quem é, especialmente para defender aquilo em que acredita

${ }_{15}$ KOLB, R. Confessing the Faith: Reformers Define the Church, 1530-1580, Saint Louis, Concordia Publishing House, 1991, p. 117. 
e confessa como membro da Igreja de Cristo. Em um contexto plural, torna-se fundamental conhecer a própria identidade. Conhecer a si próprio, suas crenças e disposições é o primeiro passo que se dá na busca da compreensão do outro. Se não houver isto, não há diálogo ecumênico, mas sim absorção e franco unionismo. Melanchton tinha a coragem de reconhecer e defender aquilo no que cria e que acreditava mostrar sua catolicidade e ortodoxia, bem como também exibia a coragem para a abertura ao diálogo e à alteridade.

Além disso, é preciso realçar o seu amor pela Igreja e pelo Evangelho. Ele entendia que a Igreja de Deus se estendia ao longo dos séculos e valorizava o testemunho e discernimento dos que vieram antes dele, buscando integrar em seu pensamento e teologia a contribuição dos Pais, valorizando seus insights e dependendo de seu testemunho para validar suas próprias conclusões ${ }^{16}$.

Vemos em Melanchton um amor pela teologia, mas também um amor pelo mundo criado por Deus. Seu espectro de conhecimento era vastíssimo e, de alguma forma, interdisciplinar. Além de seu interesse por teologia, filosofia e retórica, ele também se interessava por literatura. Introduziu história no currículo universitário, promoveu as ciências naturais em Wittenberg ${ }^{17}$. Ele tinha a consciência que não é possível amar a Deus se não se ama a este mundo por ele criado. Vemos em Melanchton um otimismo sadio, que leva a ver o mundo não apenas como um vale de lágrimas, mas como o palco onde Deus demonstra o seu amor às suas criaturas: na criação e, especialmente, em sua Palavra. Seu humanismo e otimismo servem para contrabalançar o pensamento, por vezes, excessivamente de Lutero.

Vemos também nele o interesse sincero, particular e comunitário, pelo cuidado da Igreja de Deus. Verdadeiro ecumenismo não se manifesta só nas altas esferas, mas é matéria do dia a dia. Como Kolb coloca:

Melanchthon knew that the church extended beyond the borders of his own little corner of Germany. This sense of the church as the whole household of God compelled him to reach out in dialog and concern for Christians beyond the Lutheran Reformation, for instance, to those under persecution in England or France or the Netherlands. In addition, he befriended students from outside German domains who attended Wittenberg. For a decade, he conducted Sunday

\footnotetext{
${ }^{16}$ KOLB, Philip Melanchton., p. 315. Uma obra de Referência para acessar o uso que Melanchton faz dos Pais da Igreja é FRAENKEL, P., Testimonia Patrum: The Function of the Patristic Argument in the Theology of Philip Melanchthon, Geneva, Droz, 1961.

${ }^{17}$ KOLB, Philip Melanchton, , p. 315.
} 
morning Bible study for Hungarian students who could not understand the German preaching in the Wittenberg churches. Melanchthon understood what it meant to be part of the whole household of faith. ${ }^{18}$

Enfim, para nós cristãos do século XXI, de tão variadas procedências, a característica mais importante de Melanchton que merece destaque é aquele que Markus Wriedt chama de moderatio. Ela se refere à maneira de Melanchton abordar o debate e a discussão, de forma contida, argumentativa. Não era uma fraqueza nele, mas sim uma tática de aproximação, procurando linguagem e posição para poder entrar em diálogo e buscar conquistar o oponente sem abandonar suas convicções e compreensões. Moderatio não significa apenas abrir mão do que se acredita para alcançar um acordo, mas o esforço necessário para refletir sobre as razões de sua própria posição e sobre o que os outros pensam. Por fim:

Melanchthon is an example of the sort of person of whom we could use more. Whoever had so keen an understanding and such a command of knowledge that he is sure of himself, need not hold on to his standpoint pigheadedly but rather can, with a clear head, sound out the way to compromise. ${ }^{19}$

\section{Referências Bibliográficas}

DELUMEAU, J., Nascimento e Afirmação da Reforma. São Paulo: Pioneira, 1989, traduzido por João Mendes Campos.

DINGEL, I., The Preface of the Book of Concord as a Reflection of SixteenthCentury Confessional Development, Lutheran Quarterly XV (2001), pp. 373-395.

FRAENKEL, P., Testimonia Patrum: The Function of the Patristic Argument in the Theology of Philip Melanchthon, Geneva, Droz, 1961.

KOLB, R., Confessing the Faith: Reformers Define the Church, 1530-1580, Saint Louis, Concordia Publishing House, 1991.

KOLB, R., Philipp Melanchthon: Reformer and Theologian, Concordia Journal 23 (1997), pp. 309-316.

MELANCHTON, F., Loci Communes. Saint Louis: Concordia Publishing House, 1992. Traduzido para o inglês por J.A.O. Preuss.

\footnotetext{
${ }^{18}$ KOLB, Philip Melanchton, p. 315.
}

${ }^{19}$ WRIEDT, p. 294. 
OLIN, J. C., The Catholic Reformation: Savonarola to Ignatius Loyola. New York, Fordham University Press, 1992.

PREUS, J., The Second Martin: The Life and Theology of Martin Chemnitz. Saint Louis, Concordia Publishing House, 1994.

WENGERT, T., Bearing Christ as Melanchton's Contribution to the Book of Concord, Lutheran Quarterly XV (2001), pp.396-416.

WRIEDT, M., Between Angst and Confidence: Melanchton as a Man of the Sixteenth Century, Concordia Journal 23 (1997), pp. 277-294.

Paulo Samuel Albrecht Acadêmico de Mestrado - PUC-Rio, Pastor Luterano E-mail: paulosamuelalbrecht@yahoo.com.br

Artigo Recebido em 26/08/2011

Artigo Aprovado em 28/11/2011 